\title{
Determination of Fitness Center Design Criteria with the Approach of Natural Shape and Forms in Surabaya
}

\author{
Pande Putu Dwi Novigga Artha, Bambang Soemardino, and Fransiscus Xaverius Teddy Badai Samodra \\ Department of Architecture, Institut Teknologi Sepuluh Nopember, Surabaya \\ e-mail: pandeartha69@yahoo.co.id
}

\begin{abstract}
Abstrak - Surabaya City has the highest activity and density in East Java. This situation affects physical and psychological health. Studies are stating that not exercising regularly is more dangerous than smoking. Therefore, public awareness of the importance of exercising must be increased for the health and national development. In stimulating people to be interested in visiting sports facilities is to apply the biophilic design approach. Restoring the essence of human relations with the nature can be a solution to increase enthusiasm in activities, especially sports in the city of Surabaya, that needs more natural elements. In biophilic theory, several elements can be used as design approaches, one of which is natural shapes and forms. According to Kellert's theory, the natural shapes and forms approach can be applied in 11 elements but these elements are global. By applying the theory of environmental perception, specific natural elements will be obtained with the interests of the people in Surabaya. The analysis results of the design with force-based framework method are specific design criteria for the design of the fitness center with natural shapes and forms approach. This can increase the interest in training and restore the physical and psychological health of its users.
\end{abstract}

Kata Kunci-Biophilic, Design, Fitness, Form, Natural, Shapes.

\section{INTRODUCTION}

$\mathrm{S}$ URABAYA is the capital city of East Java with a fairly high density [1]. This triggers a high level of stress for the people of the city of Surabaya. High levels of community stress affect lifestyle, especially in maintaining physical and psychological health. People are lazy to maintain physical health by exercising so that it is not yet a priority for Indonesians or the people in Surabaya [2]. According to UUD 36 Tahun 2009, health is an important component in shaping quality resources. Therefore, a substantial effort is needed to improve the health of the people of Surabaya.

The Surabaya city government has tried to hold several sports facilities both free and commercial to support public fitness. The government has held Green Open Space at several points in the city of Surabaya to minimize pollution, improve the aesthetics of the city which is expected to affect the psychological and physical health of the people of Surabaya. Every holiday or weekend season, the people of Surabaya release fatigue from the hustle and bustle of the metropolitan city of Surabaya to areas that are more beautiful and thick with natural elements such as Malang, Lamongan, Pobolinggo, and its surroundings. This resulted in a surge in vehicles on the Surabaya border toll road (Tribunnews, 2019). These things give an indicator that the people of Surabaya need and like facilities or infrastructure based on the natural environment. This gap provides an opportunity to be resolved. The provision of a fitness facility that accommodates various types of activities and ages with a natural element approach is expected to stimulate the community to exercise actively.

Natural Shape and Form is one of the 6 elements of Biophilic Design. Natural Shapes and Forms representations and simulations of the natural world that are often found in building facades and interiors. Where also explain one of the biophilic principles namely "Biophilic Design Encourages Involvement and Immersion in Fear and Natural Processes". This principle states that environments that respond to human biophilic need to use interesting and recurring experiences, learning, and social support to become an integral and beneficial part of human life [3]. The application of this principle to objects can also be made through the design of basic forms and designs using materials derived from nature such as wood, stone, soil and others [4].

Based on the data above states the importance of maintaining the physical and psychological health of the community, especially in big cities like Surabaya. The development of an increasingly modern city makes there a distance between the development of infrastructure or buildings with the needs of natural elements of society. The fact is that many facilities, especially fitness facilities, tend to be closed to sever human relations with the environment directly related to land limitations in the capital. The provision of fitness facilities with natural shapes and forms approach is a solution for developing buildings that are environmentally friendly and user friendly. However, each community has different interests based on their natural places of residence, such as in cities and villages, it tends to be different. Therefore, the importance of environmental perception theory is to find out the Surabaya people's perceptions related to natural elements of interest. The information will have a big influence on the design with the natural shapes and forms approach because with the harmony of the user's needs with the design concept, the optimal effect on health. With the natural shapes and forms approach to fitness facilities, it will become a new attraction for urban areas and attract public interest to visit and exercise so that it can improve the physical and psychological health of the people of Surabaya.

\section{METHOD}

The design of the fitness center with the natural shapes and 
The $6^{\text {th }}$ International Seminar on Science and Technology (ISST) 2020

July $25^{\text {th }} 2020$, Institut Teknologi Sepuluh Nopember, Surabaya, Indonesia

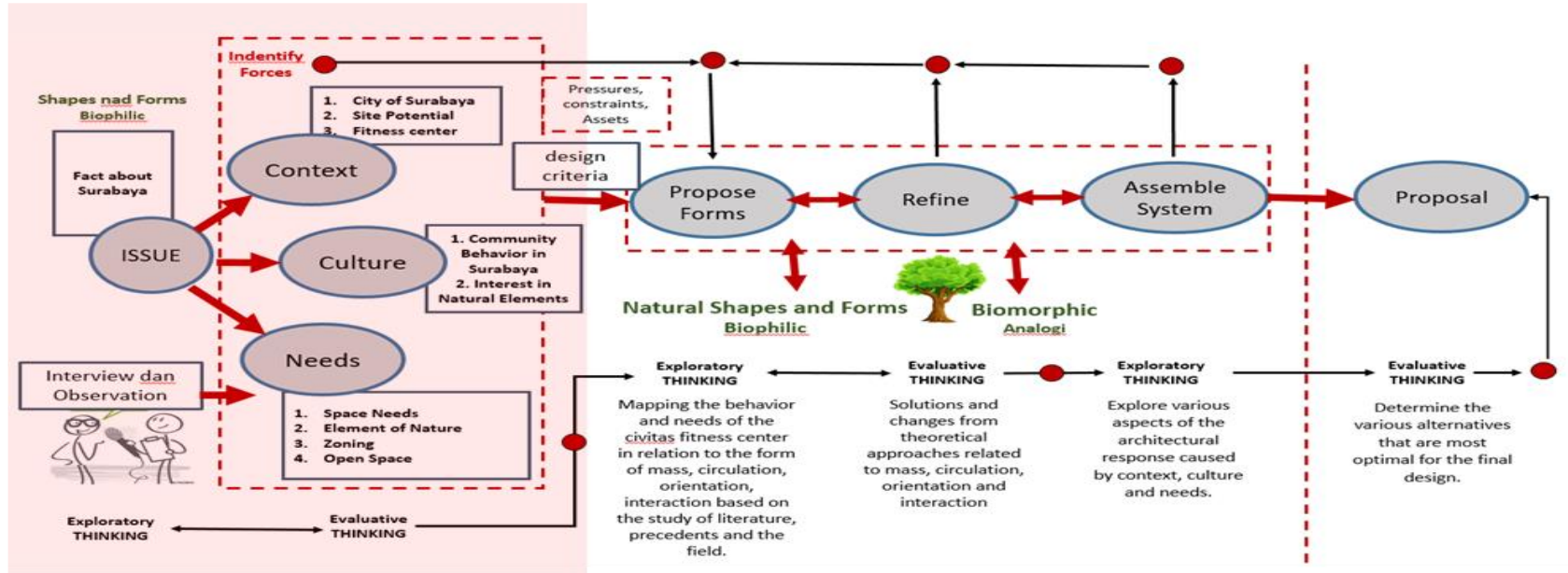

Figure 1. To get design criteria on force-based framework.

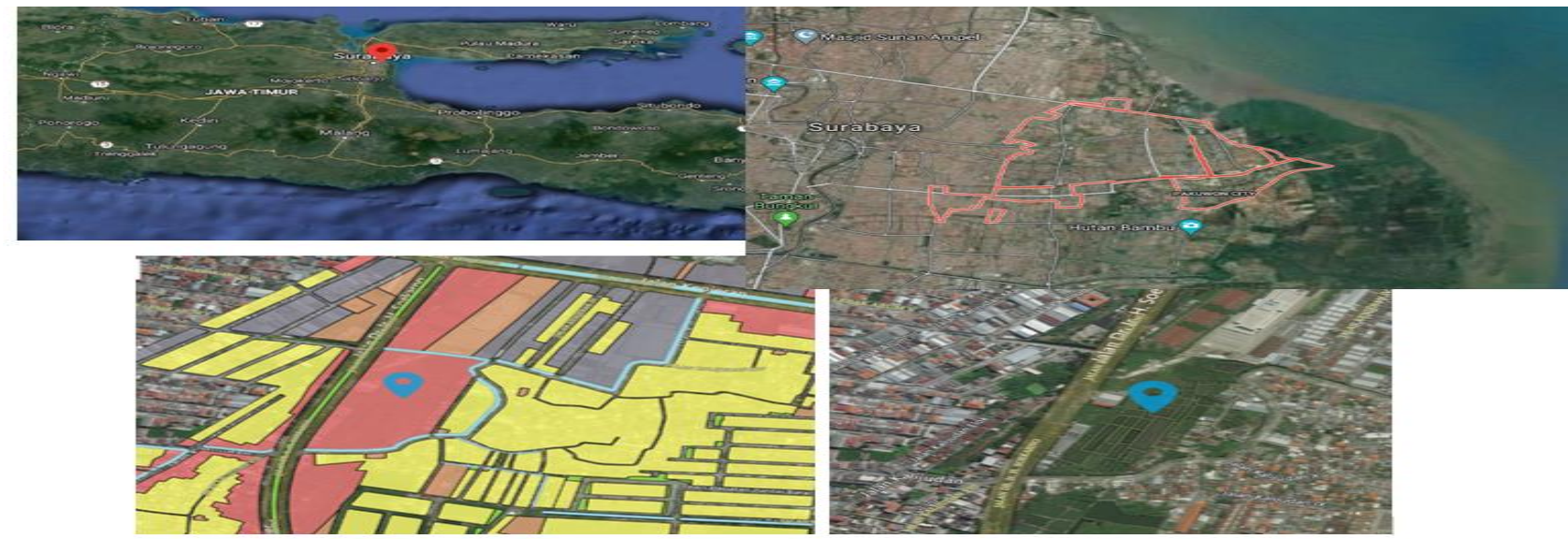

Figure 2. Site location.

forms approach in Surabaya uses the design process by Plowrig which is a force-based framework [5]. This framework becomes the guidelines and limits of the designer in creating optimal and targeted design. In general, this process is the process of analysis, synthesis, and evaluation. In a force-based framework, the process of analyzing context, culture, and needs is the first step in determining the idea or issue to be raised. After that the determination of design criteria is based on contexts, cultures and needs analysis. The second stage is the synthesis where there are propose forms, refine, and assemble system processes until the proposal is created as the final result of the design process. However, the design criteria are obtained only by the first stage of the process and combined with literature studies and precedents. The following is a diagram inspired by the design process force-based framework [5].

\section{RESULT AND DISCUSSION}

Gymnasium Based on the completeness of the fitness center is divided into 3 categories, namely: [8].

\section{A. Fitness Center Category One}

Is fitness and gymnastic facility. The available fitness equipment, in general, is very simple, not luxurious and the interior design is very ordinary or not designed at all. As with cardio tools such as treadmills and stationary bikes and a set of weight training equipment and dumbbells.

\section{B. Fitness Center Category Two}

In terms of double class, equipment is the same as a category in the fitness center, it is just that this fitness center is equipped with a steam room and a massage room.

\section{Fitness Center Category Three}

This category is considered the most complete which is often referred to as the Health Club. In addition to the sauna, spa, and swimming pool, there are quite a lot of fitness tools, complete and high quality. Specifically, fitness equipment in this category is also placed according to group exercises, for example, upper body, legs, and lower body.

Based on the above theory and to facilitate the access of the community to various kinds of sports facilities, the third category of the fitness center is the type of fitness center that is most suitable with the background of the design.

\section{Natural Shapes and Forms}

Biophilic design can reduce stress, increase creativity and clarity of mind, increase our well-being and improve wellbeing [6]. Natural shapes and forms are one of the 6 elements of Biophilic Design. This natural shapes and forms approach includes representations and simulations of the natural world that are often found in building facades and in interiors [9]. 
The $6^{\text {th }}$ International Seminar on Science and Technology (ISST) 2020

July $25^{\text {th }} 2020$, Institut Teknologi Sepuluh Nopember, Surabaya, Indonesia

Table 1.

Synthesis of Context, Culture and Needs Analysis

\begin{tabular}{ll}
\hline \hline No & Data \\
\hline 1 & Context (Land Use) \\
& Fitness Center is a commercial facility \\
that is included in the trade and services \\
\\
zone. According to Surabaya Mayor \\
Regulation Number 52 Year 2017. \\
Fitness facilities have GSB $=$ Front 4 \\
meters, GSB $=$ Side and Rear 3 meters, \\
KDB $=\max 50 \%$, TB $=15-25$ meters, \\
KDH $=\min 10 \%$.
\end{tabular}
$\mathrm{KDH}=\min 10 \%$.

2 Context (Direction of the Sun) Zones that have high levels of heat due to sun exposure are on the East and West sides. This will affect the type and placement of openings in buildings.

Context:(Wind)

The average angina speed in Surabaya reaches 6.4 Knots and a maximum of 20.3 Knots. Generally, angina comes from the West, North West and East (Surabaya.co.id; 2015)

Vegetation on the site is a banana tree, shade trees with an average height of 2.5 to 3 meters and wild shrubs. This vegetation grows on contoured land which tends to be flat. There are shady vegetation and government-owned directors on the west side of the site.
Analysis

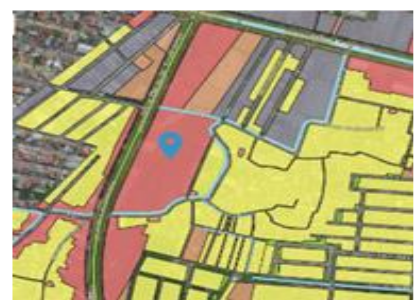

The red color represent the land designated for trade and service zones. Yellow is a settlement, health orange and office and industrial black.

Constrains:

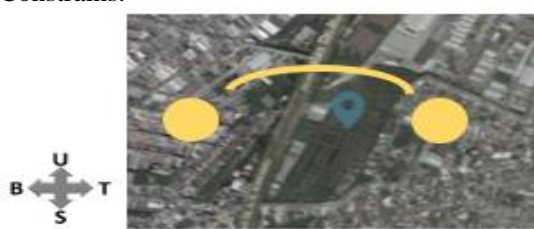

The orientation of the building entrance will be facing West because it is a highway. However, the building mass orientation will face the North, South and Middle sides of the site to avoid direct sunlight.

Constrains:

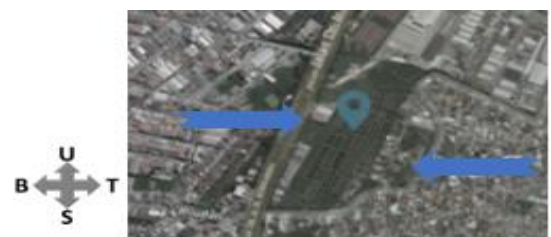

Wind circulation is very good for use in buildings to reduce the use of artificial ventilation. Then the orientation of openness to dominance is placed on the contents of the West and East.

Asset:
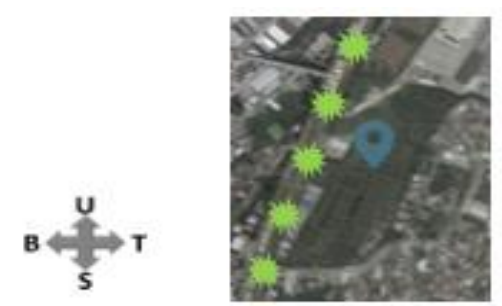

The absence of vegetation that must be maintained in a site with flat ground contours is an advantage to be able to explore the design optimally.
Synthesis

The fitness center is located at Jalan Dr. Ir. H. Soekarno, Mulyorejo District, East Surabaya. With an area of $15,000 \mathrm{~m} 2$. Based on PERWALI 52 of 2017, KDB is approximately $7,500 \mathrm{~m} 2$

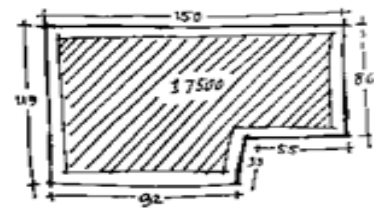

Utilization of sunlight at the Fitness Center will be adjusted to the concept and what natural elements will be applied to each room. It aims to optimize the function of space.

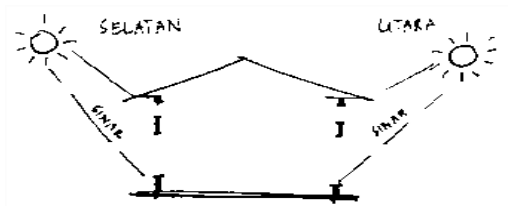

Utilization of wind in the Fitness Center will be adjusted to the function and characteristics of the room. This is based on the application of different natural elements in each space.

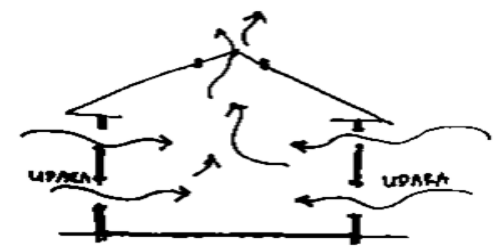

This fitness center is not dependent on existing vegetation. The type of vegetation planted will be adjusted to the needs and natural concepts that will be represented by each building and space. This is in order to create continuity between the concept of indoor and outdoor buildings.

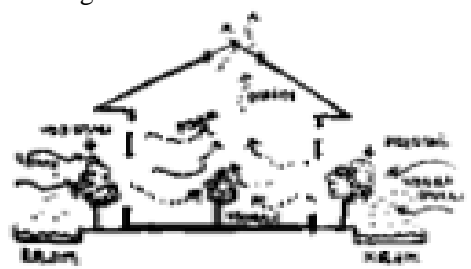


The $6^{\text {th }}$ International Seminar on Science and Technology (ISST) 2020

July $25^{\text {th }}$ 2020, Institut Teknologi Sepuluh Nopember, Surabaya, Indonesia

\begin{tabular}{|c|c|c|c|}
\hline No & Data & Analysis & Synthesis \\
\hline 5 & Context: (View) & Constraint & Fitness centers with a Natural Shapes and \\
\hline & $\begin{array}{l}\text { There is no interesting view on the } \\
\text { site because the site is in the middle } \\
\text { of the city. Site is surrounded by } \\
\text { buildings, housing, vacant land and } \\
\text { highways. }\end{array}$ & $\begin{array}{l}\text { On the south side of the site is the vacant land } \\
\text { that can be used temporarily to become a view. }\end{array}$ & $\begin{array}{l}\text { Forms approach do not merely utilize the } \\
\text { natural elements made in the building. Bu } \\
\text { there is also a design view of natura } \\
\text { elements outside the building. The outdoor } \\
\text { nature elements which will be the view are } \\
\text { expected to provide healing benefits inside } \\
\text { and outside the building. }\end{array}$ \\
\hline
\end{tabular}

6 Culture: (Civitas habits)

Each individual has different characteristics that affect the pattern of activities. Neither do the activities that they enjoy doing in sports facilities.

In addition, productive ages 16 to 30 have a high level of visits and activities compared to ages above 50 . Ages over 50 tend to come with one goal such as therapy.

7 Culture: (Interest in Natural Elements)

Most respondents were interested in the presence of natural elements in Surabaya because that was one of the things that was difficult to obtain in big

cities.

The results of the interview analysis stated that most of the community members were interested in a semiopen space. The results of observations every period during the civitas break come to an open area to breathe air or just see the surrounding environment. But for the long term the view will be designed in the middle of the site. Which is the center of orientation for all buildings in the site. Asset:

- Introvert Pattern: Come - Front Office Lockers - Go To 1 Facility - Sports Activities Rest - Sports - Lockers - Culinary - Go Home

- Extrovert Patterns: Come - Front Office Lockers - Go to Various Facilities - Sports Activities - Chat and Rest - Sports - Talk and Rests - Lockers - Hang out at the Food Court Go Home

Asset:

The people of Surabaya, especially those who like to exercise, have an interest in the natural elements in fitness building. This can refresh your mind and make you more enthusiastic in exercising.

Needs: (Space Requirement)

The results obtained from the standard, the results of interviews and observations to several fitness facilities in Surabaya.

9 Needs: (Natural Element)

Activities or types of sports can be divided into 2 namely attractive and calm sports.

Every individual has the same interests and perceptions of natural elements. This is based on the background of the dominance of the civitas in Surabaya.

Pressure:

Gym, Yoga Room, Pilates, Sauna, Badminton, Basketball, Running, Bicycles, Bowling, Swimming, Futsal, Boxing, Table Tennis, Power Lifting, Community Places, Function Rooms, Clinics, Gardens, Retail.

Pressure:

Atractive:

- An atmosphere that creates an attractive impression:

Wide, Bright, Noisy, Tall, Dynamic, Bright Color

- Natural elements:

Mountains and Beaches

Calm:

- An atmosphere that gives the impression of calm:

Quiet, Dark, Cool, Fragrant, Wide, Soft Color

- Natural elements:

Water and Vibes Batu, Malang

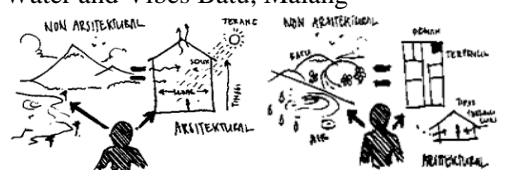

The fitness center activity pattern will be the basis for the design of space organization. The natural basic pattern is growth and the activity pattern of the community is movement. Both of these are dynamic things. This dynamic concept can be a reference in the design of space organizations in a fitness center that houses a variety of sporting and supporting activities.

Fitness center with a natural approach is created to the concept of a semi-open space. It aims to accommodate the needs of the community to be able to interact directly with natural elements such as direct exposure to sunlight, wind gusts, direct contact with vegetation, natural fresh scents and so on.

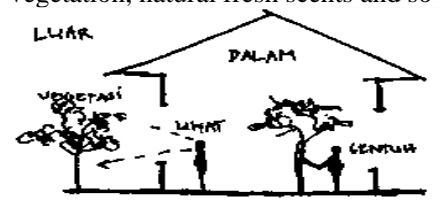

This type of space will be divided into groups that have similar characteristics. Space grouping is used to facilitate the civitas to reach and identify spaces. The grouping of space functions also serves to minimize the different characteristics of nature that collide with each other.

The perception of natural elements that are of interest to the community center community in Surabaya will be analogous to the elements of space. For example, a mountain as a representation of a room with an attractive function. So the concept of the room will be roomy (spacious), noise, loud colors / contrast and so forth. Whereas the room with calm characteristics is represented by water. The concept of the room will be calm, flowing, cool with soft colors and so on. 
The $6^{\text {th }}$ International Seminar on Science and Technology (ISST) 2020

July $25^{\text {th }} 2020$, Institut Teknologi Sepuluh Nopember, Surabaya, Indonesia

\begin{tabular}{lll}
\hline \hline No & Data & Analysis \\
\hline 10 & Needs: (Zoning) \\
This zoning is designed based on site \\
potentials such as lighting, air, view, \\
vegetation, noise that affect the site \\
zoning or zoning of a room in a \\
building. It is intended that the \\
function of space can run optimally.
\end{tabular}

11 Needs: (Open Space)

Fitness center with Natural Shape and Forms approach is a design approach with the use of artificial natural elements as an effort to increase interest in sports and health. However, this design is accompanied by openings to connect natural elements with artificial nature on site

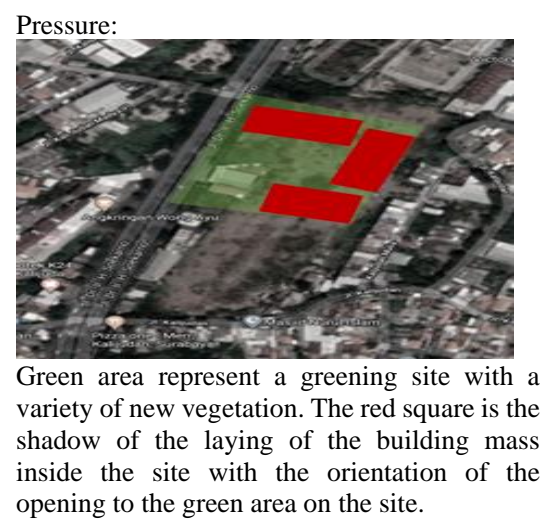

Synthesis

Buildings or spaces that have noise characteristics and public areas will be in the red zone such as Gym, Cardio, Foodcourt and others. While buildings or spaces that have quiet characteristics such as yoga rooms, pilates, saunas and so on will be in the green zone.

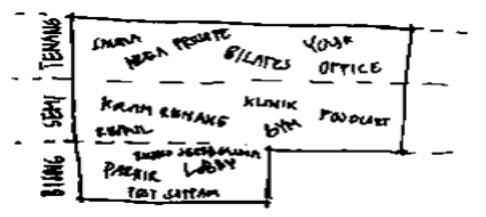

This fitness center uses a semi-open concept. It aims to restore the essence of human relations with nature. The types of openings will vary according to the function and characteristics of the space. Openings will be oriented to natural elements or vegetation within the site.

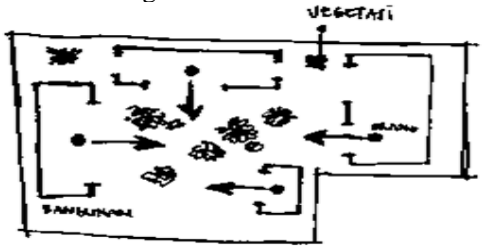

In this element, there are 11 elements or attributes in the application of natural shapes and forms, including botanical motifs, tree and columnar supports, animals (mainly vertebrate) motifs, shells and spirals, egg oval and tubular forms, arches vaults domes, shapes resisting straight lines and right angles, simulation of natural features, biomorphic, geomorphology, biomimicry [9].

However, these 11 elements are too general when applied in Indonesia, especially in Surabaya. Therefore, it is necessary to apply the theory of environmental perception. Environmental Perception, consider human-environment relations holistically and can be used to analyze subjective interpretations of the beauty or usefulness of the environment [7]. The function of applying environmental perception is to get information on what natural elements are of interest and are compatible with the character of the environment and the people of Surabaya. So if the perception of the civitas is directly proportional to the building design approach it will have a positive impact to the user.

The natural shapes and forms approach is representative of artificial natural elements. Therefore the analogy method, Biomorphic is used to transfer natural elements into architectural elements. Paul Laseau said "He showed that the analogies are easily recognized in our everyday invention [10]. The possible models from which to draw analogies can be classified by categories as physical, organic, or cultural. For the design of this fitness center using physical analogies and organic analogies. This is motivated by facilitating the civitas in capturing messages from designs that apply the natural shapes and forms approach.

The object of design is the Fitness Center with the Natural Shapes and Forms Approach which aims to improve the health of the people of Surabaya by exercising. The design location is in the District of Mulyorejo, East Surabaya. It is a district with a fairly high density. There are various facilities in the district, including offices, settlements, malls, museums, schools, universities, and so on. This density is an asset whereby building a building with a natural approach it becomes a refresher from a modern city and is certainly accessible from anywhere. The boundaries of the existing site are: North: Commercial Area and Kenjeran Family Partner Hospital, East: Citizens Settlement, South: Commercial and Housing Areas, West: Jalan Raya Dr.Ir.H. Soekarno, Surabaya.

\section{E. Forces Identification}

The results of identification forces consist of the analysis of context, culture, and needs in which several aspects need to be considered in the formulation of criteria design. These various aspects will be classified into constraints, pressure, and assets in the design. The data is obtained from observations, interviews, precedent studies, and literature reviews. The following is an analysis of each of the forces displayed through the table 1 .

Based on the table 1, it can be concluded that the Design of Fitness Center with the Natural Shape and Form Approach in Surabaya has:

1. Constraint is the Direction of the Sun, Wind, View 
The $6^{\text {th }}$ International Seminar on Science and Technology (ISST) 2020

July $25^{\text {th }} 2020$, Institut Teknologi Sepuluh Nopember, Surabaya, Indonesia

2. Pressure is land use, space requirements, natural elements, zoning and openings

3. Asset is Vegetation, Civitas Habit and Interest of Natural Elements

Based on the discussion above, the precedent study, literature study, context, culture and need analysis determine the design criteria of the fitness center with natural shapes and forms approach, which is:

1. Fitness center is categorized as fitness center category 3 with a natural perspective approach that accommodates various ages, both productive age (16-30) to nonproductive age.

2. The design approach uses the theory of Biophilic, Natural Shapes and Forms. So the design concept is not only limited to connections with natural elements but also created from artificial natural elements.

3. Sports activities are divided into 2 attractive and calm categories. Both of these categories have the closeness of natural elements according to the perception of the Surabaya people. The design concept was applied to the indoor and outdoor elements of the building. The theory used in the formation of design is Biomorphic.

4. It is important to pay attention to the placement of fields, views, orientation and arrangement of vegetation related to the advantages and disadvantages of the site. So that all the natural potentials around the site are able to give a positive impact in the building related to the theory of Natural Shapes and Forms specifically.

\section{CONCLUSION}

The main point of this journal is that the building designs in Surabaya are able use the Biophilic, Natural Shapes and Forms approach. However, in applying this approach, it is important to pay attention to the forces, especially the perception of the building user community. In this journal example, the application of natural shapes and forms from natural elements of mountains and beaches can stimulate the active activist community and natural elements of water and atmosphere of Batu, Malang can stimulate calm while exercising. So the application of biophilic design with the context of the city of Surabaya can give a positive impact on users.

\section{ACKNOWLEDGMENT}

Thank you to the manager of Atlas Sport Center, Gold Gym Sutos Surabaya and Mercure Grand Mimara Gym for the information and ease in location surveys for precedent studies. Thank you also for interview respondents for information related to activities, facilities and natural elements of interest in Surabaya.

\section{REFERENCES}

[1] RPJMD. 2016. Rencana Pembangunan Jangka Menengah Daerah (RPJMD) Kota Surabaya 2016-2021.

[2] Prasetyo, Y. 2013. Kesadaran Masyarakat Berolahraga Untuk Peningkatan Kesehatan Dan Pembangunan Nasional. Jurnal . FIK UNY.

[3] Kellert, S. 2018. Nature By Design, The Practice of Biophilic Design. U.S. Public Press.

[4] Ikvan dan Wawanm, 2017. Desain Ruang Relaksasi untuk Stres di Perkotaan dengan Penerapan Biophilic Design. Jurnal Sains dan Seni Pomits. ITS.

[5] Plowright. 2014. Revealing Architectural Design, Methods, Frameworks and Tools. New York. Routledge.

[6] Terrapin Bright Green. 2014. 14 Pattern of Biophilic Design: Improving Health \& Well Being In The Built Environment. Washington, DC: Authors.

[7] Dak Kopec. 2018. Enviromnetal Psychology For Design 3rd Edition. Bloomsbury Publishing Inc. New York.

[8] Christiany P. 2015. Perancangan Interior Pada Fitness First Di Mall Pacific Place Jakarta (skripsi). Jakarta (ID): Binus University.

[9] Kellert, S. R. 2008. Dimensions, Elements, Attributes of Biophilic Design (pp3-19). In S. F. Kellert, J. H. Heerwagen, \& M. L. Mador (Eds.), Biophilic Design. Hoboken, NJ: Wiley.

[10] Laseau, Paul. 2001. Graphic Thinking for Architects \& Designers. Canada : John Wiley and Sons. 